\title{
OPPORTUNITIES AND CHALLENGES FOR PROCUREMENT IN BIG DATA AND ARTIFICIAL INTELLIGENCE
}

\section{SANTOSH BEHERA \& SRIKANTA SAHOO}

Department of Management, Siksha 'O' Anusandhan (Deemed to be University), Bhubaneswar, Odisha, India

Received: Jun 06, 2020; Accepted: Jun 26, 2020; Published: Aug 26, 2020; Paper Id.: IJMPERDJUN2020893

\section{INTRODUCTION}

The procurement now has advanced tremendously as compared to its earlier status in the mid twentieth century, which was of a predominantly manufacturing sector. Initially it was described as a department that was solely responsible for the acquisition of goods and services, however there was massive change that happened in the 1980s and 1990s due to the increase in prices in a global market which was increasing rapidly[1]. The purchasing sector has clearly depicted its advance to strategic importance. Now as the business environment is speedily changing across continents and borders, it is being a mandatory trend to change and diversify according to the changing needs of the customers and hence competitive pressure on organizations are part of "Hybrid Supply Chain Networks"[2], which are getting affected by "Big Data", "Internet of Things" and "Artificial Intelligence". In today's world, organizations are facing revolutionary change which is the result of the global interconnectivity and real time transfer of data which allows the firms to create new business models and drive for more innovation to remain in the business [3]. The disruptive and ever evolving "digitization" is the talk of the town and every industry be it organizations, politics, management or non-profit organizations. The main business unit function and supply chain activity which nowadays plays the most vital role in this digital age is Procurement[4].

Procurement is a continuous sequence of multiple coordinated activities in order to obtain the different resources including raw materials, skills, and facilities to perform the core business activities. It is the initial step in any business transaction and basically the mediator between internal and external business environment. Talking 
about the external resource business environment, procurement was defined as the external source for sustaining and handling the most suitable conditions of a company[5]. Procurement is the backbone of any company and ensures that all the products and services have been purchased before hand for a smooth and convenient process. In other way it can be that procurement management is being cautious of delays and errors in deliveries etc. Procurement has always been about planning ahead and being cohesive in nature, whether it is internally or externally. A typical old-style procurement process would include specification and planning, identifying the potential suppliers and after critically examining and scrutinizing, selecting the suppliers. This is a very crucial step as here many elements such as cost, delivery items, social responsibility, quality control, safety of the workers etc. all should be kept in mind like request for proposal, negotiating, contracting, check for on time deliveries and track the same. Last but not the least measurement analysis, as through this a firm will be able to assess the competency and overall success of the process [6].

\section{DISCUSSIONS}

\section{Procurement Processes}

The procurement is a set of standard steps that need to be followed in order to make business and for smooth functioning of the workflow. There is no standard process and it can change according to one's need and desire. The following are the basic steps that comprise of the procurement process:

\section{Identification of Needs}

The first and foremost is the need of any material and the specifications of the product. It is of utmost importance to have a clear idea as to what all is the requirement and how much is needed.

\section{Selection of Vendors}

After one has decided of the material requirements, the next step comprises of selecting a suitable vendor who complies with all the specifications and is ready to supply the goods. This the most crucial step of procurement as the supplier needs to be assessed on many factors like price, lead time, delivery, and whether or not the supplier is in compliance with the company's code of ethics.

\section{Developing a Sourcing Strategy}

A lot has been talked about sourcing strategy and how procurement professionals want to gain advantage through developing effective sourcing strategies. One needs to source the right goods to meet the business requirements. Having a strong sourcing strategy is mandatory as it can help in reducing cycle time, leverage best practices and gain spend visibility and control.

\section{Contract Management / Negotiation}

After selection the suppliers and creating a robust sourcing strategy, the next step is negotiating and conducting various bids in order to have the best price. Every business starts with the aim of profit and therefore every effort is made in having the lowest price unit of every product. This way maximum benefit can establish with less amount of money. This is the step where RFP and RFQ are sent and contracts are made on the basis of the decisions.

\section{Order Fulfillment}


The subsequent step after contract management is of order fulfilment. This simply means the act of receiving and delivering the final orders to the final client. The purchase orders are hence fully received and then starts with the process of receipts and finally invoicing. This shall be succeeded by budget tracking as well in later steps.

\section{Supplier Evaluation and Supplier Relationship Management}

This is the last step of the procurement cycle and it consists of supplier evaluation after the order has been duly fulfilled and received. This is done in order to rate the performance of the supplier on different criteria and the company also can decide whether to continue the business with the existing supplier or not.

\section{Procurement in the Age of Digitalization}

Procurement is dramatically changing today and is revolutionizing its old traditional methods. With the more and more emerging technologies purchasing department is shifting to a more strategic approach and is no longer just about buying and selling products. The purchase and sale of supplies that is done in any business to business engagement, which involves an internet platform is known as an e-procurement activity. The major drift from paper-based system to e procurement is to enhance the productivity of the entire process. One of the major objectives of this is to reduce the cost and enhance the efficiency of the workflow. A great number of research and study is being conducted in this area as it has a lot of potential and all industries are optimistic to improve their procurement process using the current intelligence and technology. It also talks about the semantic based E procurement and ontology-based e procurement systems and defines how public and private marketplaces could benefit from it[6].

Also, it is believed that Artificial Intelligence has a direct link on the purchase and advertising[7]. Using real time data one can determine what is the exact quantity that is needed by the company and if there are any changes in the plan the quantity ordered can be altered. This is only done through AI and can change the price of inventory accordingly.

The term "Internet of things" was started in late 1990s and after that it has only got more hyped and the talk of the town. The questions that have been raised are, what is the true meaning of this technology for the purchasing department and what are the impacts it does possess? The major question is not what the implications are but what should be done in order to prepare the procurement for such implications? Generically according to Wikipedia "The Internet of Things (IOT) is a network of physical objects or things embedded with electronics, software, sensors and connectivity to enable to achieve greater value and service by exchanging data with the manufacturer, operator and/or other connected devices. Each thing is uniquely identifiable through its embedded computing system but can interoperate within the existing Internet infrastructure. The interconnection of these embedded devices (including smart objects) is expected to usher in automation in nearly all fields[8].

Digital technologies will change how the work is conducted with the help of different tools and help in procurement collaboration. These tools can range from a large variety along the entire value chain from planning, sourcing and contract negotiations and supplier management. The companies offering such facilities should also note down that they are solely responsible for the decisions and ensuring that using big data will maximize their growth and potential. It also mentions that no matter what the strategy is, the ideal digital procurement process includes digital request for quotations, e-signatures and verifications, procurement risk analysis, supplier financial analysis and procurement collaboration.

The resources that are needed for future to be competitive enough have already been known and are evaluated by the industries in the era of digitization. It can also be said that the process has already begun and is going to shape the structure 
of tomorrow's supply chain ecosystems. It does not matter what is the size of the organization or what type of industry it belongs to, the only thing is that the digital transformation and innovation will create a disruption within the supply chain models. It also mentions that apart from all this technological innovation and increasing collaboration, there are two vital things "trust" and "security" that will play a major role in the future. Firstly, cybersecurity comes as a priority because as all the transactions will be automated it automatically will pose a great threat to the data protection and therefore the firms need to have good cybersecurity systems in order to combat such situations. Secondly, trust between two parties (buyer supplier relationships) would also influence the success of the digital transformation where virtual information becomes a reality[4].

\section{Big Data in Procurement}

After discussing the various opportunities in procurement, supply chain as shown in Figure 1 is another big sector where technologies like big data have disrupted the industries. The people in this industry are heavily researching and finding new methods to demonstrate the opportunities it possesses and how big data can make the supply chains more customer centric, data driven. It also states certain examples to elaborate the effective use of big data. Big data solutions are being used in the organizations to integrate and help elevate the business planning methods and become more proactive towards the growing trends. With the help of real time data, organizations can get vital information related to the sales, current trends and preferences of the customers, demographic and geographical data and all these inputs helps the supply chain professionals in taking decisions that are predictive in nature. One other most important use of the technology is that it helps in predicting the delays in deliveries and by GPS data it can take preventive measurements and therefore avoid the delays that occur due traffic and weather conditions and take smart moves to optimize the delivery routes. Further these applications can use the efficiency by analyzing preventive maintenance, the behavior of the driver, vehicle routing, accessing the fuel productivity. UPS uses an application named ORION "On-Road Integrated Optimization and Navigation) that facilitates the drivers in finding the best route to deliver the goods[9].

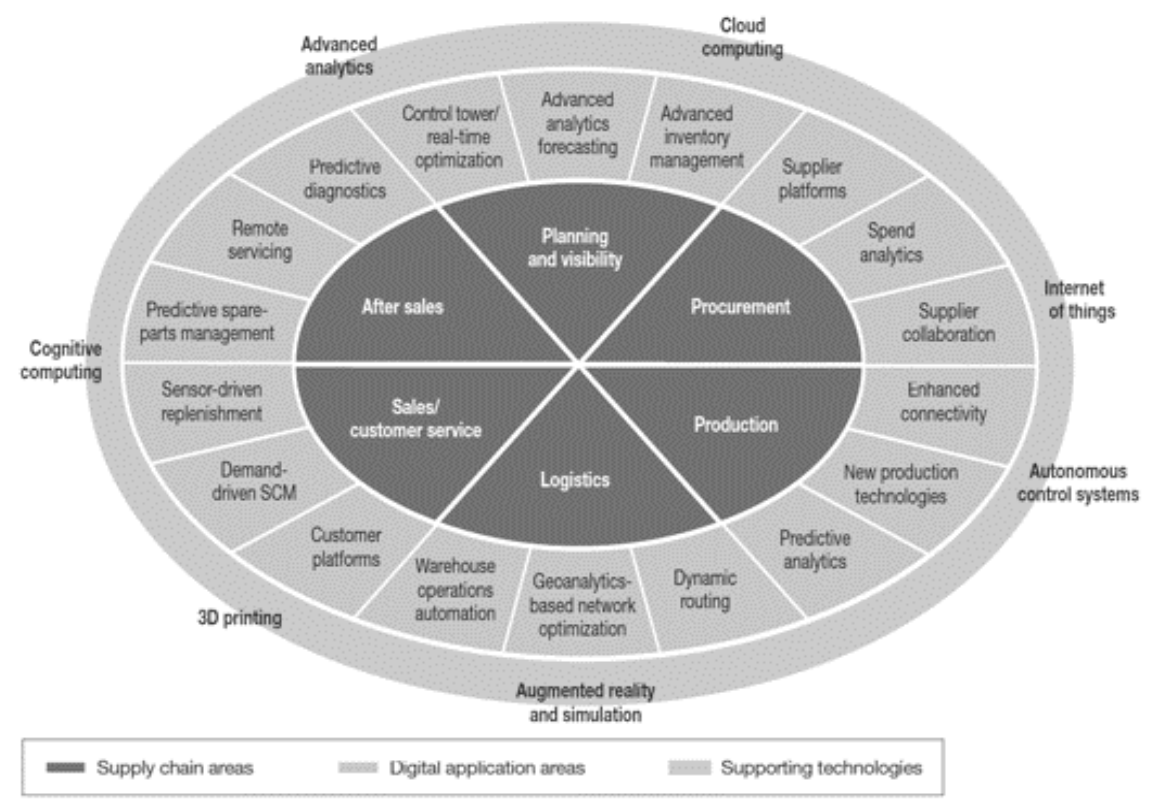

Figure 1: Industrial Sectors in Technology.

Big data possesses the feature of predictive analytics which is the heart of big data. Imagining cig data as a large chunk of data and with the help of predictive analysis, it utilizes the data and make predictions based on the data provided. This predictive analysis uses different data handling techniques and helps in making predictions on the information shared 
in real time. This characteristic has a lot of potential and help solving various big issues.From a procurement perspective it can help in strategic sourcing and predict the demand of the stock and make it available at the best price available without compromising the quality and other factors. This way smarter decisions are applied on the basis of the historical data that has been provided.

\section{Artificial Intelligence in Procurement}

Imagine a situation where there is snow outside and you cannot go to work anymore. The smartphone has become this smart that knowing it is a holiday, it starts recommending you schedule the meetings for the next day and also suggests movies that you could watch. This is a very small example of how Artificial Intelligence can enter daily lives and make lives easy. The technology has immense promising features and it provides us an opportunity to rediscover and reimagine the user experience. The machine with the help of humans can learn and replicate the processes in a much more efficient manner and using the abundant data sources can make life easier for business units[10].

Similarly, there are numerous ways Artificial Intelligence can affect the ways procurement has been doing its tasks. It is known that there is still a long way to go in order to achieve full automation in how procurement adapts these emerging technologies like Artificial Intelligence. The technology has the potential to transform the old traditional methods and the management can utilize their time in taking strategic decisions. Be it AI guided chat bots or automated negotiations in contract management, it is helping the procurement professionals in many ways. One more example is of the real time tracking shipment option which with the help of processed data can enhance the productivity[7].

AI is a concept that was coined many years ago, however the trend has been highlighted only since few years ago. Artificial Intelligence has multiple layers of varied technologies in it. For example, robotic process automation, machine learning and natural language processing and all these add different contexts to the overall AI. One cannot expect AI to become a massive success overnight and solve the world's greatest problem, however if trained well by humans it can do wonders which are beyond human capabilities.

As procurement function shifts from being simply a buyer towards a more strategic role, it can take advantage of the immense data set and which ultimately can result in better sourcing opportunities with the help of automation. With the help of AI companies can get away with the monotonous work and can outsource the same to the machines which can work 24/7 and still show the same amount of productivity. Similarly, in sourcing, the chatbots can be implemented that can serve the various queries of the suppliers and hence managers can target on the much more strategic areas. AI also plays a great role in helping the procurement experts by visualizing the data and helping in getting to know how much has already been spent to a certain supplier, and what are the potential threats with that supplier etc. and lower the cost in the long run.

\section{Challenges and Opportunities for Procurement}

As mentioned earlier, the digital transformations are not limited to product-based markets and also extends to the service industry. It is not far that traditional methods will become obsolete and using less pay per use will become the sole motive of every business firm. Here comes the importance of change management, as no digital transformation is complete or let us say successful without having set plans for change management. This can be considered the biggest challenge for supply chain as well as procurement professionals. The workforce needs to add new skill set which will become the essence of any business firm. E-Procurements surely has a lot of advantages to the companies are on the right track of digitalization, reduction in the cost of the transactions, better spend visibility and more productive performances are a few to mention. It 
reduces the transaction costs as every employee is given the freedom to order the products directly from supplier catalogue, and this entire process is transparent and makes each individual responsible for his order. By doing so every employee can order according to his ordering level and saves time. Paperless activities further solve the environmental issues and add to the CSR of the company. The good news is that the buyers can negotiate and select the best deal given by the supplier as it can use data and see which supplier offers the best deals. But as this area is changing at a great pace there are some people who believe that it as a threat to the procurement sector as people are not fully aware of the technology and how to make full use of it. Professionals are hesitant with adapting this new method of working and all know that denial of adapting a certain change can lead to the failure of the approach. Adding to it, one of the major risks is the cost attached to the installation of the process. Digital transformations consume a lot of money as well as time and the company can only afford when it is fully ready for it. A strategic way should be adopted that will further lead to the success of the project[1].

The first and foremost step is to be done away with the old methods of performing the activity and to have prior knowledge of the process and how it is to be managed in complex situations. Also, which ERP will be suitable for the industry and what will be the work flow all needs to be considered well in advance. Then comes the second step which is to channelize the internal process or in the technical term is also known as Business Process Reengineering. This step is useful as the companies will get to know the steps carefully and break down the business processes.

However, with every great step comes a set of challenges and even in this process it isn't a smooth journey. Firstly, it is expensive, and needs to have a separate budget to install the technology. Secondly ROI should be calculated because if there is no return on investment there is no use in investing such a big amount and putting all at stake. Thirdly, comes the famous "bullwhip effect", as the real time data would create a lot of changes and it is very important that people understand the market well and do not fall prey.

\section{CONCLUSIONS}

Technology has entered in every sphere of life and there is no running away from it. Change is the only constant and this quote aptly defines the changing scenario of procurement sector as well. Technologies like artificial intelligence and big data have shown a lot of potential and that is the sole reason that companies are trying their hands on it. It will open a lot of new doors in the future and will help in connecting all the dots in the value chain. From purchase ordering, demand forecasting, inventory management, sourcing to supplier evaluation, every area is impacted and benefitted from AI and big data. With the ever flowing real time information and knowledge, companies have a perfect solution for finding a way to achieve their dream where top management can concentrate on more strategic issues and hence deriving value.

The influence of digitization towards an organization as well as the digital transformation within the organization itself has an impact towards existing procedures, processes, capacities, and capabilities. Therefore, organizations, managers, and employees are faced with several challenges and organizations have to provide an appropriate business environment to overcome these barriers by considering the different internal and external stakeholders. Hence, common processes are required to ensure a transparent flow of information, goods, and cash. According to the survey, organizations have to consider the existing procedures and processes from a system point of view as well as the current communication tools and channels to determine areas of improvement to handle the digital transformation.

\section{REFERENCES}

1. G. R. T. White, S. Parfitt, C. Lee, and R. Mason-Jones, “Challenges to the Development of Strategic Procurement: A Meta- 
Analysis of Organizations in the Public and Private Sectors, " Strateg. Chang., 2016.

2. M. E. Porter and J. E. Heppelmann, “How smart, connected products are transforming competition,” Harvard Business Review. 2014.

3. L. Downes and P. Nunes, "How the Internet Saved Handmade Goods, ” HBR Harvard Business Review, $2014 .$.

4. F. Bienhaus and A. Haddud, "Procurement 4.0: factors influencing the digitisation of procurement and supply chains," Bus. Process Manag. J., 2018.

5. R. Y. Zhong, S. T. Newman, G. Q. Huang, and S. Lan, "Big Data for supply chain management in the service and manufacturing sectors: Challenges, opportunities, and future perspectives," Comput. Ind. Eng., 2016.

6. J. M. Alvarez-Rodríguez, J. E. Labra-Gayo, and P. O. De Pablos, "New trends on e-Procurement applying semantic technologies: Current status and future challenges, " Comput. Ind., 2014.

7. J. Kietzmann, J. Paschen, and E. Treen, “Artificial intelligence in advertising: How marketers can leverage artificial intelligence along the consumer journey, "Journal of Advertising Research. 2018.

8. C. Mantey, “Jump on the Internet of Things Bandwagon or Get Left in the Dust., " Supply Demand Chain Exec., 2015.

9. N. R. Sanders, "How to use big data to drive your supply chain," Calif. Manage. Rev., 2016.

10. T. Lau, "When AI Becomes a Part of Our Daily Lives," Harv. Bus. Rev., 2019. 
